\title{
Le terrorisme antineuronal des radicaux libres
}

Comme on pouvait s'y attendre, l'identification de mutations dans le gène codant pour la superoxyde dismutase $\mathrm{Cu} / \mathrm{Zn}$ (SODl) dans des formes familiales de sclérose latérale amyotrophique $[1,2]\left(m / s n^{\circ} 4\right.$, vol. 9, p. 469 et $n^{\circ} 5$, vol. 9, p. 643) a stimulé les recherches sur le rôle des radicaux libres oxygénés dans les mécanismes de mort neuronale [3]. On sait que cette enzyme catalyse la réaction par laquelle les $\mathrm{O}_{2}{ }^{\text {- }}$ sont transformés en $\mathrm{H}_{2} \mathrm{O}_{2}$ que catalase et glutathion peroxydase peuvent ensuite transformer en eau et oxygène (figure 1). Les résultats présentés dans deux articles récents viennent justifier spectaculairement cet intérêt en associant un déficit ponctuel induit en SODl et des atteintes neuronales. Ces deux articles, produits par l'équipe de Jeff Rothstein (Johns Hopkins University, Baltimore, USA) et par Carol Troy et Michael Shelanski (Columbia University, New York, USA), examinent les mécanismes par lesquels la perte de SOD 1 induit la mort neuronale. Troy et Shelanski [4] ont utilisé des oligonucléotides antisens pour bloquer la synthèse de SODl dans des cellules PC12 en culture. Une baisse de $40 \%$ de l'activité de l'enzyme conduit effectivement à une rapide mort cellulaire liée à des mécanismes d'apoptose. L'addition dans les cultures de vitamine E (un antioxydant) inhibe le phénomène, ce qui confirme le rôle des radicaux libres oxygénés. Il est intéressant de constater que l'addition d'un facteur neurotrophique, le NGF, qui induit une différenciation neuronale des $\mathrm{PC} 12$, n'a pas d'effet protecteur et semble même favoriser l'atteinte cellulaire. Rothstein et al. [5] ont, pour leur part, travaillé sur des cultures organotypiques de moelle épinière qu'ils ont traitées à l'aide d'oligodésoxynucléotides antisens ou d'un chélateur métallique inhibiteur de la SOD1, le DDC (diéthyldithiocarbamate). Comme attendu, l'inhibition de la synthèse de SODl a provoqué, après quatre semaines, la mort par apoptose des motoneurones. L'effet, cifique de cette population neuronale. Le DDC, quant à lui, a été efficace dès la dose de $1 \mathrm{mM}$, induisant alors, là aussi, une mort neuronale apoptotique à la quatrième semaine. Dans ces conditions, comme dans celles de Troy et Shelanski, l'atteinte neuronale pouvait être bloquée par l'addition d'agents antioxydants et dépendait donc de la mobilisation de radicaux oxygénés. Elle pouvait aussi, toutefois, être bloquée partiellement par l'action d'antagonistes de récepteurs non NMDA du glutamate, soulignant l'existence vraisemblable d'une interaction entre des mécanismes associés à l'excitotoxicité du glutamate et ceux découlant de l'action des radicaux libres oxygénés, interaction encore affirmée par l'additivité des effets toxiques du DDC et d'un inhibiteur de recapture du glutamate.

On peut tirer de ces résultats des conclusions extrêmement intéressantes quant aux mécanismes de la mort neuronale et aux désordres moléculaires susceptibles de les soustendre. Il est clair, d'abord, que les neurones sont sensibles à une diminution, même très partielle, de l'activité d'une enzyme de détoxification de l'oxygène. Les expériences réalisées tant avec le NGF qu'avec les agents modifiant l'effet du glutamate semblent indiquer que le stress oxydatif induit par le fonctionnement neuronal lui-même requiert une activité enzymatique optimale de la SOD. Il n'existe apparemment que peu d'espace de liberté entre cette activité optimale et l'activité maximale en conditions normales. Ces données suggèrent évidemment que l'introduction d'un gène codant pour la forme native de SODl, aboutissant à un accroissement de l'activité maximale de l'enzyme dans les neurones, pourrait avoir un effet neuroprotecteur. Une "thérapie génique " à but détoxifiant est bien évidemment en germe dans ces travaux, aussi bien pour les maladies motoneuronales que pour d'autres maladies neurodégénératives, voire pour les atteintes neuronales postischémiques pour lesquelles des mécanismes excitotoxiques et/ou de toxicité de l'oxygène ont été suggérés. Cependant, une telle perspective n'est probablement pas encore à portée de main. Sur le plan théorique, tout d'abord, la figure 1 rappelle qu'en l'absence d'une activité suffisante des catalases ou de la glutathion peroxydase, l'eau oxygénée produite par la SOD peut donner naissance à des radicaux hydroxyles $(\mathrm{OH} \bullet)$ fortement toxiques par l'intermédiaire de la réaction HaberWeiss qui est catalysée par le fer. Par ailleurs, les résultats obtenus ex vivo par les équipes de Baltimore et de New York [4, 5] ne sont peut-être pas pertinents pour comprendre les mécanismes responsables des formes familiales de sclérose latérale amyotrophique. En effet, Rothstein et al. et Troy et Shelanski attribuent l'effet toxique observé sur des cellules et tissus nerveux à une perte partielle de fonction de la SOD, alors que les résultats de Gurney et al. [6], récemment commentés dans médecine/sciences $\left(\mathrm{m} / \mathrm{s} n^{\circ} 8-9\right.$, vol. 10 , p. 914), étaient en faveur d'un mécanisme par "gain de fonctions " dans lequel une propriété nouvelle de la SOD mutée, et non la diminution de l'activité de la forme normale, serait cause de la dégénérescence. En effet, ce dernier travail décrivait une lignée de souris transgéniques (et, à vrai dire, une seule), synthétisant la SOD murine normale et une grande quantité de SOD humaine avec la mutation Gly ${ }^{93} \rightarrow$ Ala, et développant une atteinte dégénérative progressive des motoneurones qui ne pouvait être attribuée à un déficit en SOD, puisque le mutant utilisé avait une activité presque normale et que les animaux transgéniques avaient une activité SOD totale augmentée. L'hyperactivité de la SOD ne semblait pas, non plus, être en cause, car des animaux possédant plusieurs copies du gène humain normal étaient asymptomatiques.

En bref, des résultats multiples confirment que les radicaux libres dérivés de l'oxygène et la SOD sont impliqués dans des phénomènes de neurodégénérescence, mais les ano- 


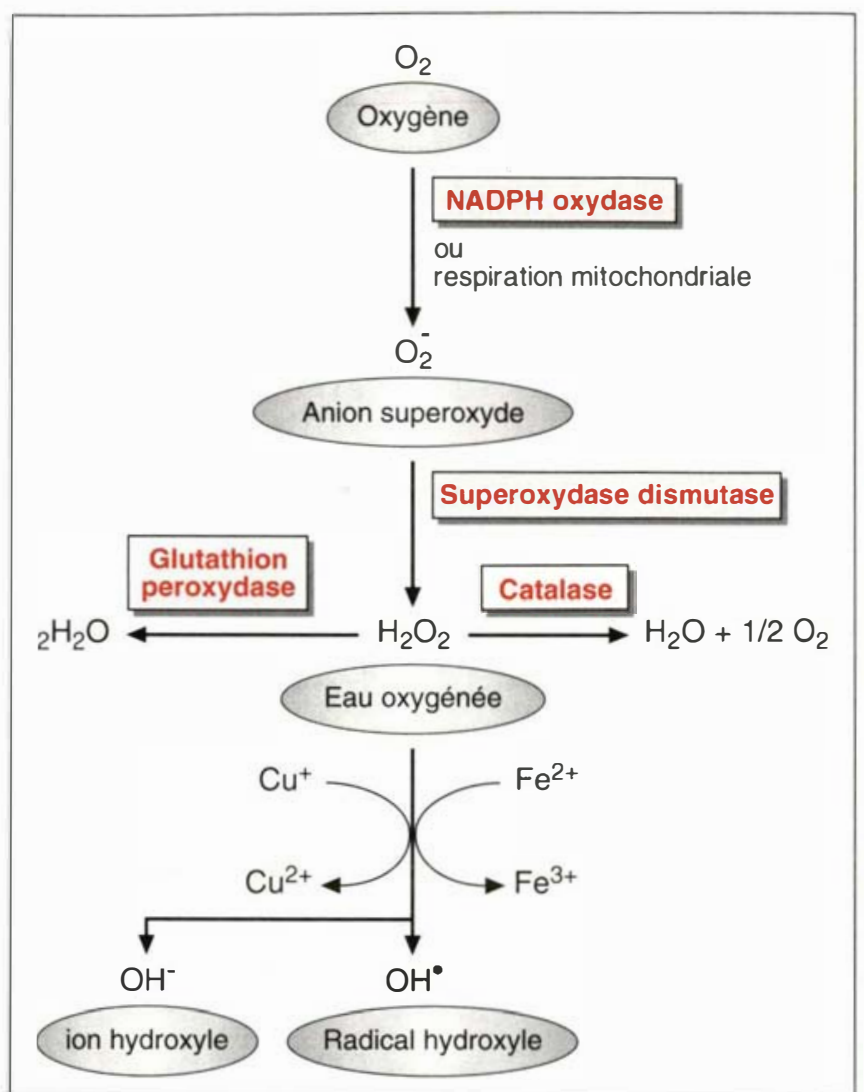

Figure 1. Schéma indiquant les différentes étapes aboutissant à la formation ou à l'élimination de radicaux libres oxygénés (en milieu aqueux). malies réellement causes des lésions et des symptômes ne sont ni parfaitement connues, ni comprises ; on imagine bien que l'approche thérapeutique sera différente selon qu'il s'agit d'augmenter une activité de détoxification des radicaux libres ou d'inactiver une enzyme produisant des composés toxiques.

M.P. 3. Kahn A. Bel-2 inhibe-t-il l'apoptose en s'oppoM.P. sant à laction des radicaux oxyene? A.K. médecine/sciences $1994 ; 10: 208-9$.
4. Troy CM, Shelanski MI. Down regulation of copper/line superoxide dismutase causes apoptotic death in PC.12 neuronal cells. Pror Natl Acad Si LSt 1994: $91:(3384-7$

5. Rothstein JD), Bristol IA, Hosler B, Brown RH, hunel RW. (hronic inhibition of superoxide dismutase produces apoptotic death of spinal neurons. Proc Natl Acad Sir ('SA 1994:91:415\%-9.

6. Gunney ME. Pu H, Chiu AY, et al. Motor neuron degeneration in mice that express a human C.u, \%n superoxide dismutase mutation. Science $1994: 264: 1772-5$. 